\title{
Holistic Analysis of Coronavirus Literature: A Scientometric Study of the Global Publications Relevant to SARS-CoV-2 (COVID-19), MERS-CoV (MERS) and SARS-COV (SARS)
}

\author{
Engin Şenel, MD (1); Fatih Esad Topal, MD
}

ABSTRACT

Objectives: In late December 2019, a cluster of patients with pneumonia caused by an unknown pathogen was reported from Wuhan, Hubei Province, China. The pathogen has been identified as a novel coronavirus, severe acute respiratory syndrome 2 (SARS-CoV-2) and the disease has been named as coronavirus disease 2019 (COVID-19). The objective of this study was to perform the first holistic scientometric evaluation of coronavirus publications.

Methods: Our main source for this study was Web of Science Collection database. All items published between 1980 and 2019 were included. A distribution map of global production in coronavirus literature and scientometric networks were generated.

Results: The United States, China, Germany, the United Kingdom, and Netherlands were the most productive countries. Publications in coronavirus literature have been produced from almost every country in the world, except for some countries in Asia and Africa.

Conclusion: While in the 1980s, the United States and developed countries from Europe were major source countries and the virus was identified only as an animal disease in the literature and its biological and genetic structure was investigated, in the 2000s, China became a major contributor of coronavirus literature because the SARS outbreak originated from southern China. Almost all most-cited publications in this period are related to SARS and the ACE2 protein.

Key Words: bibliometrics, coronavirus, COVID-19, MERS, SARS, SARS-CoV-2, SARS-CoV, scientometrics

$\mathrm{I}$ n late December 2019, a cluster of cases with pneumonia caused by an unknown etiology was reported from Wuhan, Hubei Province, China. ${ }^{1}$ Later, the cause of the disease was identified as a novel betacoronavirus, the 2019 novel coronavirus (2019-nCoV). The disease was coined as coronavirus disease 2019 (COVID-19). Recently, the official name of the virus that causes COVID-19 has been announced by World Health Organization (WHO) as severe acute respiratory syndrome coronavirus 2 (SARS-CoV-2). ${ }^{2}$

Scientometrics, also known as "Science of science," is a popular statistical method analyzing scientific literature thoroughly in a certain field. ${ }^{3}$ The academic literature lacks an in-depth scientometric study evaluating coronaviruses and disease caused by them. Herein, we aimed to perform a holistic scientometric assessment of the coronavirus literature.

\section{METHODS}

Our main source of this study was Web of Science (WoS, Thomson Reuters, New York, NY) Core Collection database. We preferred WoS as our main data source because it provides data analysis for publications and citations and allows the results to be sorted according to the number of citations. In addition, WoS attribution data are considered more reproducible and reliable than other databases, and WoS is used as the standard by certain official organizations. ${ }^{4}$ We used keywords of "coronavirus," "SARS", "SARS-CoV", "MERS", "MERS-CoV", and "COVID-19" for our analysis. All items published between 1980 and 2019 were included, and documents produced in 2020 were excluded for our major analysis. A distribution map of global production of coronavirus literature was generated by a free Web source named GunnMap. ${ }^{5}$ VOSviewer freeware was used to create scientometric networks. ${ }^{6}$ 


\section{RESULTS}

\section{General Features of Coronavirus Literature}

A total of 13,833 documents indexed in WoS Core Collection between 1980 and 2019 were found in coronavirus literature, 7339 of which were open access. The peak year for publication was 2016 with 837 papers and 106 articles have been produced in 2020 so far. English was the major language of coronavirus literature $(96.957 \%)$ followed by French, German, Spanish, and Chinese $(0.802,0.766,0.289$, and 0.231 , respectively). Original articles covered $80.518 \%$ with 11,138 documents of all coronavirus literature followed by reviews, proceeding papers and editorials $(8.545,4.634$, and $2.704 \%$, respectively; Table 1). Virology, Veterinary Sciences, and Infectious Diseases were the most studied areas in literature (Table 1).

\section{Performances of the Countries, Authors, Institutions, and Sources}

The United States of America (USA) ranked first in coronavirus literature with 4894 articles (35.379\%) followed by China, Germany, the United Kingdom (UK) and the Netherlands $(16.663,6.701,6.448$, and $5.711 \%$, respectively). Publications in coronavirus literature have been produced from almost every country in the world, except for some countries in Asia and Africa (Figure 1). Yuen from the University of Hong Kong (China) was the most prolific author with 218 indexed papers $(1.576 \%$, Table 1$)$. University of Hong Kong was also detected as the most productive institution in the literature with 534 publications (3.86\%; Table 1). Journal of Virology, Virology and Advances in Experimental Medicine and Biology were the most contributor source titles in coronavirus literature $(N=1166,510$, and 370 items, respectively; Table 1 ).

\section{Citations, Decades, and Scientometric Networks Analyses 1980-1989}

Our search yielded 641 articles in the period of 1980 to 1989. The United States, Federal Republic of Germany, the United Kingdom, Canada, and France dominated coronavirus literature in this period $(36.661,13.417,12.168,9.204$ and 7.8 , respectively). The most prolific author was Termeulen $\mathrm{V}$ with 37 items. The Journal of General Virology and University of Würzburg (Germany) stood out in their categories in this period. $\mathrm{H}$-index of coronavirus literature for this period was calculated as 79 and total number of citations was 21,682 (18,643 without self-citations). Average citations per item were 33.83. The most cited document in this period was an original article titled "Characterization of An Efficient Coronavirus Ribosomal Frameshifting Signal - Requirement for An RNA Pseudoknot" written by Brierley et al. (Table 1).

\section{0-1999}

Coronavirus literature had 1674 documents indexed between 1990 and 1999. The United States, Germany, Canada, the
United Kingdom, and the Netherlands were the most productive countries between 1990 and 1999 (44.265, 8.961, 8.303, 8.244, and 7.826, respectively). Lai from University of Southern California (USA) was the most prolific author with 70 documents. The Journal of Virology was the prominent source title in this decade with 226 articles (13.501\%), and University of Southern California (USA) was the most contributor institution with 96 papers $(5.735 \%)$. H-index was measured as 105 and published documents were cited 63,445 times in this period (53,214 without self-citations). The most cited document was an original article titled "Community Study of Role of Viral-Infections in Exacerbations of Asthma In 9-11-Year-Old Children" by Johnston et al. (Table 1). As we analyzed scientometric network analysis of coronavirus literature in this period the most indexed keywords were detected to be "coronavirus," "mouse hepatitis virus," "transmissible gastroenteritis virus," "rotavirus," and "cat" (Table 1).

\section{0-2009}

A total of 4810 documents was produced in coronavirus literature between 2000 and 2009, and $82.682 \%$ of all items were original articles. The United States, China, Canada, Germany, and Netherlands were the most productive countries $(N=1679,1202,324,322$, and 278 papers, relatively). University of Hong Kong (China), Chinese Academy of Sciences (China), and Chinese University of Hong Kong (China) were the most contributor institutions in this period (5.925, 4.595, and 3.576\%, respectively). Yuen form the University of Hong Kong (China) was the most prolific author with 110 papers $(2.287 \%)$ and the most productive source titles were detected to be Journal of Virology, Virology and Advances in Experimental Medicine and Biology (10, 3.493 and $3.222 \%$, respectively). H-index for this decade was 165 and total number of citations was 189,424 (135,829 without self-citations). Average citations per item were 39.38. The most cited article in this period was an original article written by SARS Working Group, Ksiazek et al., titled "A novel coronavirus associated with severe acute respiratory syndrome" published in The New England Journal of Medicine in 2003 (Table 1). The most indexed keywords were detected to be "coronavirus," "SARS-CoV," and "spike protein" (Table 1). Scientometric network map of the most used keywords showed a starburst pattern in which the keywords of "coronavirus," "SARS," "SARS coronavirus," and "SARSCoV" centered.

\section{0-2019}

The decade of 2010s was the most active period of the literature with 6601 documents. Most documents $(N=4146$; $62.8 \%$ ) were open access and $80.7 \%$ of all items were original articles. The United States, producing $33.586 \%$ of all coronavirus literature, ranked first as ever, followed by China, Germany, Saudi Arabia, and The United Kingdom (22.406, $6.575,6.454$, and $6.166 \%$, respectively). University of 
TABLE 1

\begin{tabular}{|c|c|c|}
\hline \multicolumn{3}{|l|}{ Features of Coronavirus Literature } \\
\hline & Number & $\%^{b}$ \\
\hline \multicolumn{3}{|l|}{ Document Types } \\
\hline Original article & 11,138 & 80.518 \\
\hline Review & 1,182 & 8.545 \\
\hline Proceedings paper & 641 & 4.634 \\
\hline Editorial material & 374 & 2.704 \\
\hline Meeting abstract & 344 & 2.487 \\
\hline Book chapter & 291 & 2.104 \\
\hline Letter & 256 & 1.851 \\
\hline Note & 185 & 1.337 \\
\hline News item & 82 & 0.593 \\
\hline Correction & 55 & 0.398 \\
\hline Early access & 34 & 0.246 \\
\hline Book & 6 & 0.043 \\
\hline Correction & 3 & 0.022 \\
\hline Data paper & 1 & 0.007 \\
\hline \multicolumn{3}{|l|}{ Research Areas } \\
\hline Virology & 4411 & 31.888 \\
\hline Veterinary sciences & 2093 & 15.130 \\
\hline Infectious diseases & 1613 & 11.661 \\
\hline Immunology & 1558 & 11.263 \\
\hline Microbiology & 1519 & 10.981 \\
\hline Biochemistry & 1347 & 9.738 \\
\hline Biotechnology & 816 & 5.899 \\
\hline Experimental & 658 & 4.757 \\
\hline Multidisciplinary sciences & 598 & 4.323 \\
\hline Internal medicine & 459 & 3.318 \\
\hline \multicolumn{3}{|l|}{ Top 10 Authors } \\
\hline Yuen KY (The University of Hong Kong, China) & 218 & 1.576 \\
\hline Perlman S (University of lowa, USA) & 189 & 1.366 \\
\hline Enjuanes L (Autonomous University of Madrid, Spain) & 176 & 1.272 \\
\hline Baric RS (University of North Carolina, USA) & 171 & 1.236 \\
\hline Weiss SR (University of Pennsylvania, USA) & 150 & 1.084 \\
\hline Drosten C (Berlin Institute of Health, Germany) & 148 & 1.070 \\
\hline Rottier PJM (Utrecht University, The Netherlands) & 134 & 0.969 \\
\hline Woo PCY (The University of Hong Kong, China) & 129 & 0.933 \\
\hline Chan KH (The University of Hong Kong, China) & 122 & 0.882 \\
\hline Lau SKP (The University of Hong Kong, China) & 120 & 0.867 \\
\hline \multicolumn{3}{|l|}{ Top 10 Institutions } \\
\hline University of Hong Kong (China) & 534 & 3.860 \\
\hline Chinese Academy of Sciences (China) & 396 & 2.863 \\
\hline Utrecht University (The Netherlands) & 335 & 2.422 \\
\hline University of California System (USA) & 333 & 2.407 \\
\hline National Institutes of Health (USA) & 328 & 2.371 \\
\hline University Of North Carolina (USA) & 273 & 1.974 \\
\hline Centers for Disease Control Prevention (USA) & 258 & 1.865 \\
\hline Chinese University of Hong Kong (China) & 229 & 1.655 \\
\hline University Of North Carolina (USA) & 223 & 1.612 \\
\hline University of Pennsylvania (USA) & 216 & 1.561 \\
\hline \multicolumn{3}{|l|}{ Top 10 Source Titles } \\
\hline Journal of Virology & 1166 & 8.429 \\
\hline Virology & 510 & 3.687 \\
\hline Advances in Experimental Medicine and Biology & 370 & 2.675 \\
\hline Journal of General Virology & 330 & 2.386 \\
\hline Archives of Virology & 263 & 1.901 \\
\hline Emerging Infectious Diseases & 245 & 1.771 \\
\hline Virus Research & 245 & 1.771 \\
\hline PLOS One & 239 & 1.728 \\
\hline
\end{tabular}




\section{Continued}

Veterinary Microbiology

Journal of Virological Methods

Total
Number

198

171

13,833
$\%$

1.431

1.236

100
Top Cited Manuscripts

Article

Characterization of An Efficient

Coronavirus Ribosomal

Frameshifting Signal -

Requirement for An RNA

Pseudoknot

Coronaviruses - Structure and

Genome Expression

The Biology and Pathogenesis

of Coronaviruses

Completion of The Sequence of The Genome of The Coronavirus Avian Infectious-Bronchitis Virus

Pathogenicity of Antigenic Variants of Murine Coronavirus JHM

Selected with Monoclonal-

Antibodies

Isolation of Coronavirus Envelope

Glycoproteins and Interaction with

The Viral Nucleocapsid

An Efficient Ribosomal

Frame-Shifting Signal in The

Polymerase-Encoding Region

of The Coronavirus IBV

The Biology of Coronaviruses

Coronavirus Genome - Prediction of

Putative Functional Domains in

The Non-Structural Polyprotein

by Comparative Amino-Acid

Sequence-Analysis

Proteolytic Cleavage of The

E2-Glycoprotein of Murine

Coronavirus - Activation of

Cell-Fusing Activity of Virions

by Trypsin and Separation Of

2 Different 90k-Cleavage

Fragments

Community Study of Role of

Viral-Infections in Exacerbations of

Asthma In 9-11-Year-Old Children

Psychological Stress and

Susceptibility to The

Common Cold

Respiratory Viruses and

Exacerbations of Asthma

in Adults

Lelystad Virus, The Causative Agent of Porcine Epidemic Abortion and

Respiratory Syndrome (Pears), Is

Related

to LDV and EAV

\section{Author}

Brierley, I; Digard, P; Inglis, SC

1980-1989 (n=641)

Cell

Wege, $\mathrm{H}$; Siddell, S; Termeulen, V

Boursnell, MEG; Brown,

TDK; Foulds, IJ; et al.

Fleming, JO; Trousdale, MD;

Elzaatari, FAK; et al.

Brierley, I; Boursnell, MEG;

Binns, MM; et al.

Siddell, S; Wege, H; Termeulen, V

Gorbalenya, AE; Koonin, EV;

Donchenko, AP; et al.

$1990-1999(n=1674)$

Johnston, SL; Pattemore, PK;

Cohen, S; Tyrrell, DAJ; Smith, AP

Nicholson, KG; Kent, J; Ireland, DC

Meulenberg, JJM; Hulst, MM;
Total Citation

Average Citations per Year

466

14.56

Spaan, W; Cavanagh, D; Horzinek, MC Journal of General Virology

393

11.91

Current Topics in

Microbiology and

Immunology

Journal of General Virology

302

8.88

Journal of Virology

266

7.60

Sturman, LS; Holmes, KV; Behnke, J Journal of Virology

EMBO Journal

Journal of General Virology

Nucleic Acids Research

6.97

Sturman, LS; Ricard, CS; Holmes, KV Journal of Virology

215

5.97

51.08

33.50

28.43

21.68
British Medical Journal

Sanderson, G; et al.

New England Journal

1005

British Medical Journal

796

Virology

607

1328

Demeijer, EJ; et al.

Lai, MMC; Cavanagh, D

Advances in Virus Research

545

22.71 
Continued

Top Cited Manuscripts

\section{Article}

The Molecular Biology of

Coronaviruses

Isolation and Direct

Characterization of Resident

Microglial Cells from The Normal

and Inflamed Central-Nervous-

System

RNA Recombination in Animal

and Plant-Viruses

Porcine Reproductive and

Respiratory Syndrome Virus

Comparison: Divergent Evolution

on Two Continents

Human Aminopeptidase- $N$

Is A Receptor for Human

Coronavirus-229e

Aminopeptidase-N Is A Major

Receptor for The

Enteropathogenic Coronavirus

TGEV

A novel coronavirus associated with severe acute respiratory syndrome

Identification of a novel coronavirus in patients with severe acute respiratory syndrome

Characterization of a novel coronavirus associated with severe acute respiratory syndrome Coronavirus as a possible cause of severe acute respiratory syndrome

The genome sequence of the

SARS-associated coronavirus

Cloning of a human parvovirus by molecular screening of respiratory tract samples

Angiotensin-converting enzyme 2 is a functional receptor for the SARS coronavirus

Isolation and characterization of viruses related to the SARS coronavirus from animals in Southern China

Bats are natural reservoirs of SARSlike coronaviruses

Clinical progression and viral load in a community outbreak of coronavirus-associated SARS pneumonia: a prospective study

Isolation of a Novel Coronavirus from a Man with Pneumonia in Saudi Arabia

Hospital Outbreak of Middle East Respiratory Syndrome

Coronavirus

Human infections with the

emerging avian influenza A H7N9

Author

Sedgwick, JD; Schwender, S; Imrich, $\mathrm{H}$; et al.

Lai, MMC

Nelsen, CJ; Murtaugh, MP; Faaberg, KS

Yeager, CL; Ashmun, RA; Williams, RK; et al.

Delmas, B; Gelfi, J; Lharidon, R; et al. Nature

Drosten, C; Gunther, S; Preiser, W; et al. et al.

Peiris, JSM; Lai, ST; Poon, LLM; et al.

Marra, MA; Jones, SJM; Astell, CR;

et al.

Allander, T; Tammi, MT; Eriksson, M; et al.

Li, WH; Moore, MJ; Vasilieva, N; et al.

Guan, Y; Zheng, BJ; He, YQ; et al.

Li, WD; Shi, ZL; Yu, M; et al.

Peiris, JSM; Chu, CM; Cheng, VCC; et al.

Zaki, Ali Moh; van Boheemen, Sander;

Assiri, Abdullah; McGeer, Allison; Perl,
New England Journal of Medicine

Rota, PA; Oberste, MS; Monroe, SS; $\quad$ Science

Lancet

1439

Science

1274

Science

Science

Lancet

New England Journal of Medicine

New England Journa of Medicine

544 


\section{Top Cited Manuscripts}

\section{Article}

virus from wet market poultry:

clinical analysis and

characterization of viral genome

Dipeptidyl peptidase 4 is a

functional receptor for

the emerging human

coronavirus-EMC

Viral pneumonia

Impacts of Bioinformatics to

Medicinal Chemistry

Genomic Characterization of a

Newly Discovered Coronavirus

Associated with Acute Respiratory

Distress Syndrome in Humans

Epidemiological, demographic, and

clinical characteristics of 47 cases

of Middle East respiratory

syndrome coronavirus disease

from Saudi Arabia: a descriptive

study

Middle East respiratory syndrome

coronavirus neutralising serum

antibodies in dromedary camels: a

comparative serological study

Middle East Respiratory Syndrome

Coronavirus (MERS-CoV):

Announcement of the Coronavirus

Study Group
Author

Raj, V. Stalin; Mou, Huihui; Smits,

Saskia L.; et al.

Ruuskanen, Olli; Lahti, Elina;

Jennings, Lance C.; et al.

Chou, Kuo-Chen

van Boheemen, Sander; de Graaf,

Miranda; Lauber, Chris; et al.

Assiri, Abdullah; Al-Tawfiq, Jaffar A.; Al-Rabeeah, Abdullah A.; et al.

Reusken, Chantal B. E. M.; Haagmans, Bart L.; Mueller,

Marcel A.; et al.

de Groot, Raoul J.; Baker, Susan C.; Baric, Ralph S.; et al.
Journal Name/Published in

Nature

467

58.38

Lancet

448

44.80

Medicinal Chemistry

379

63.17

mBio

362

40.22

Lancet Infectious Diseases

360

45.00

Lancet Infectious Diseases

350

43.75

Journal of Virology

330

41.25

\section{0-1999}

1 Coronavirus $(64,125)$

2 Mouse hepatitis virus $(48,93)$

3 Transmissible gastroenteritis virus, $\operatorname{TGEV}(12,39)$

4 Rotavirus $(11,27)$

Cat $(9,30)$

Feline infectious peritonitis $(9,24)$

RT-PCR $(9,14)$

$\operatorname{MHV}(9,12)$

Demyelination $(8,18)$

Infectious bronchitis virus $(8,12)$

Porcine $(7,22)$

Gastroenteritis $(7,20)$

Feline coronavirus $(7,14)$

Porcine respiratory virus $(6,20)$

Virus $(6,17)$

Diagnosis $(6,15)$

Diarrhea $(6,12)$

Pig $(6,11)$

$\begin{array}{ll}19 & \text { Serology }(5,14) \\ 20 & \text { Macrophage }(5,13)\end{array}$
Top Used Keywords (Occurrences, total link strength) 2000-2009

Coronavirus $(430,934)$

Severe Acute Respiratory Syndrome, SARS,

SARS-CoV $(314,584)$

Spike protein $(67,159)$

Nucleocapsid protein $(56,131)$

Infectious bronchitis virus $(59,117)$

Vaccine $(43,106)$

Epidemiology $(41,92)$

RT-PCR $(42,86)$

Rhinovirus $(32,85)$

Diagnosis (32, 79)

Respiratory syncytial virus $(25,76)$

ACE2 $(29,72)$

Influenza $(25,71)$

Children $(29,69)$

Monoclonal antibody $(23,63)$

IBV $(24,62)$

Recombination $(20,55)$

Diarrhea $(29,54)$

Bovine coronavirus $(27,52)$

Rotavirus $(19,52)$

\section{0-2019}

Coronavirus $(765,1176)$

Middle East Respiratory Syndrome,

MERS-CoV $(367,577)$

Epidemiology $(136,238)$

Severe Acute Respiratory Syndrome, SARS, SARS-CoV $(122,172)$

Porcine epidemic diarrhea virus $(112,131)$

Infectious bronchitis virus $(104,106)$

Vaccine $(92,187)$

Spike protein $(90,188)$

Phylogenetic analysis $(85,110)$

Respiratory virus(es) $(83,107)$

Saudi Arabia $(74,156)$

Influenza $(69,127)$

Feline coronavirus $(68,68)$

Diagnosis $(60,102)$

Respiratory syncytial virus $(58,114)$

Feline infectious peritonitis $(57,61)$

Pneumonia $(56,97)$

Children $(55,88)$

Bat(s) $(53,84)$

Recombination $(49,91)$

a Total percentage may exceed $100 \%$ because certain items were included in more than 1 category.

${ }^{\mathrm{b}}$ Of total documents published in coronavirus disease literature. 


\section{FIGURE}

\section{Publication Density of World Countries in Coronavirus Literature.}

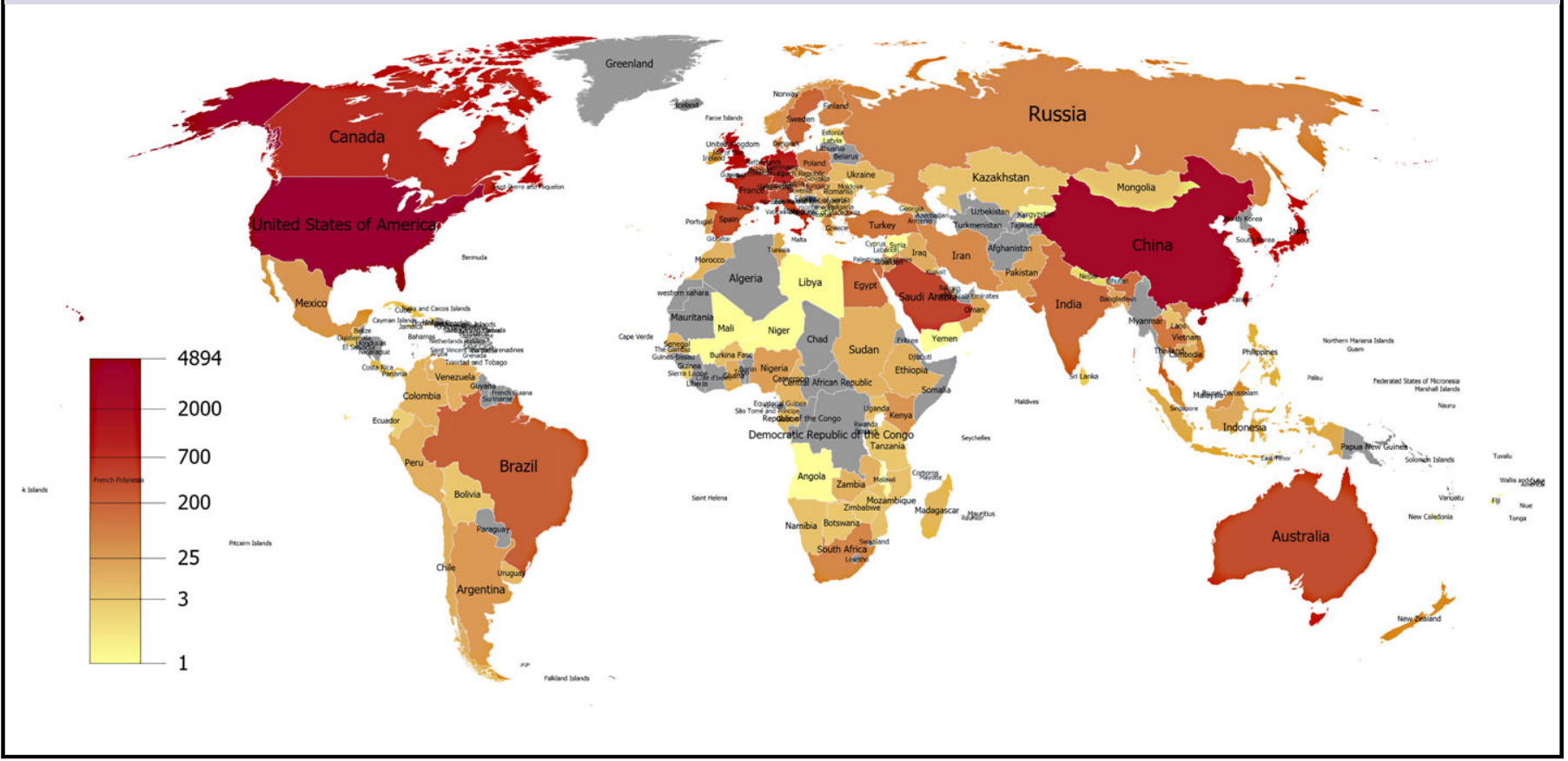

Hong Kong (China), National Institutes of Health (USA), Chinese Academy of Sciences (China), and University of California System (USA) stood out from the rest (3.681, $2.787,2.575$, and $2.439 \%$, respectively) and Drosten from Charité - Universitätsmedizin (Germany) was the most prolific author of this period with 113 articles. A total of 6111 articles were analyzed for the citation analysis. $\mathrm{H}$-index of this period was measured as 106. Indexed documents were cited 109,418 times (53,521 times without self-citations). An original article titled "Isolation of a Novel Coronavirus from a Man with Pneumonia in Saudi Arabia" written by Zaki indexed in The New England Journal of Medicine in 2012 (Table 1). The most indexed keywords were "coronavirus," "MERS-CoV," "epidemiology," and "SARS-CoV" (Table 1). Scientometric network analysis of keywords revealed relative keywords such as "Saudi Arabia," "MERS-CoV," "outbreak," vaccine," "camel," and "zoonosis."

\section{Update for 2020 and COVID-19 (SARS-CoV-2)}

By the date of the writing of this study (May 15, 2020), 6679 documents were indexed relevant to CoVid-19 in PubMed and 4605 items were included in WoS databases. All included documents were published and indexed in 2020. Total number of open-access coronavirus articles produced in 2020 was 4605. China ranked first with 1184 documents $(25.711 \%)$ followed by the United States, the United Kingdom, Italy, Germany, India, Canada, Australia, France, Iran, Switzerland,
Brazil, and South Korea (23.822, 9.511, 9.186, 4.039, $3.757,3.735,3.648,3.409,3.062,2.953,2.323$, and $2.237 \%$, respectively). The most contributor institutions were University of London (UK), Huazhong University of Science Technology (China), Harvard University (USA), University of California System (USA), Wuhan University (China), University of Hong Kong (China), Chinese Academy of Sciences (China), Zhejiang University (China), University of Oxford (UK) and Fudan University (China) (3.149, $2.758,2.193,2.172,2.041,1.781,1.694,1.607,1.433$, and $1.39 \%$, respectively). Major source titles for 2020 were Lancet, British Medical Journal, Journal of Medical Virology, Nature, Science, and Cureus ( $N=135,119,108,95,89$, and 78 items, respectively).

\section{DISCUSSION}

It is important to analyze the coronavirus literature based on periods, because it helps us understand the progression of the disease. In the 1980s, the United States and developed countries from Europe were major source countries. During this period, the virus was identified only as an animal disease in the literature, and its biological and genetic structure was investigated. In the second decade we investigated (1990s), the United States and European countries stood out again and the coronaviruses started to be examined in terms of whether it affected the health of animals and people with asthma (Table 1). In fact, in this period, the effects of these 
viruses on the human respiratory system were underlined in the literature and perhaps early measures could be taken for a possible global eradication of coronaviruses. Of course, this is just our hypothetical and speculative interpretation.

The 2000s can be called as the SARS period in the coronavirus literature. In November 2002, a novel respiratory system disease coined as SARS was identified in China caused by SARS-CoV. This disease caused global anxiety, because it progressed through an outbreak and epidemic in 26 countries and more than 8000 people were affected. ${ }^{7}$ In the literature of the 2000s, China became a major contributor of coronavirus literature because the SARS outbreak originated from Guangdong province of southern China. Almost all most-cited publications in this period are related to SARS and ACE2 protein. SARS-CoV is "thought to be an animal virus from an as-yet-uncertain animal reservoir, perhaps bats, that spread to other animals (civet cats)" according to WHO. We want to draw attention to one of the most cited articles in this period titled "Bats are natural reservoirs of SARS-like coronaviruses" written by Li et al. published in Science in 2005 (Table 1). The authors reported that species of bats were a natural host of coronaviruses closely related to those responsible for the SARS outbreak. In the conclusion paragraph of this manuscript, $\mathrm{Li}$ et al. suggested in-depth investigation of reservoir host distribution, animal-animal and human-animal interaction (particularly within the wet-market system), and analyzing genetic diversity of bat-borne viruses to avoid future outbreaks. $^{8}$

In April 2012, a novel lethal zoonotic pathogen, MERS-CoV, was identified in humans in Saudi Arabia and Jordan. A total of 2499 confirmed cases and 858 deaths (mortality rate, $34.3 \%$ ) were reported from 27 countries. Outbreaks caused by human-human transition in Saudi Arabia in 2014 and South Korea in 2015 occurred. ${ }^{9}$ In 2010s, Saudi Arabia became one of the major sources in coronavirus literature. Almost all most-cited articles were related to MERS in this period.

We found only one scientometric document relevant to coronavirus literature. It was a letter with limited data and no tables or images revealing scientometric networks. The authors reported that the United States and China had primary roles in the literature. ${ }^{10}$

\section{CONCLUSIONS}

In late 2019, a novel coronavirus causing SARS-like pneumonia was identified. This novel virus was temporarily named as SARS-CoV-2 and the disease has been coined as COVID-19 by the $\mathrm{WHO} .^{2} \mathrm{By}$ the date of writing this study, a total of 167,682 confirmed patients and 6456 deaths were reported from 157 countries and territories, and the COVID-19 outbreak has been officially declared as pandemic. We hypothesized that the COVID-19 pandemic could be prevented if the suggestions of the articles previously published, such as that by Lie et al., were taken into consideration and the wetmarkets were completely closed to cut off the human-animal interaction. Scientometric studies should be performed in certain diseases that previously caused epidemics to prevent global spread in the future and to take urgent measures.

\section{About the Authors}

Hitit University Faculty of Medicine, Department of Dermatology and Venereology, Çorum, Turkey (Dr Şenel); Hitit University, Traditional and Complementary Medicine Application and Research Center, Çorum, Turkey (Dr Şenel) and Katip Çelebi University Ataturk Training and Research Hospital, Department of Emergency, Izmir, Turkey (Dr Topal).

Correspondence and reprint requests to Engin Şenel, Hitit University, Faculty of Medicine, Department of Dermatology and Venereology, 19200 Çorum, Turkey (e-mail: enginsenel@enginsenel.com).

\section{Conflict of Interest}

None declared.

\section{REFERENCES}

1. Huang C, Wang Y, Li X, et al. Clinical features of patients infected with 2019 novel coronavirus in Wuhan, China. Lancet. 2020;395(10223): 497-506. doi: 10.1016/S0140-6736(20)30183-5

2. World Health Organization. Naming the coronavirus disease (COVID-19) and the virus that causes it. https://www.who.int/emergencies/diseases/novelcoronavirus-2019/technical-guidance/naming-the-coronavirus-disease(covid-2019)-and-the-virus-that-causes-it. Accessed March 15, 2020.

3. Hood WW, Wilson CS. The literature of bibliometrics, scientometrics, and informetrics. Scientometrics. 2001;52(2):291-314. doi: 10.1023/A: 1017919924342

4. Kendall S. LibGuides: PubMed, Web of Science, or Google Scholar? A behind-the-scenes guide for life scientists. Which one is best: PubMed, Web of Science, or Google Scholar? https://libguides.lib.msu. edu/c.php?g=96972\&p=627295. Accessed March 15, 2020.

5. GunnMap. GunnMap 2. http://lert.co.nz/map/. Accessed January 10, 2020.

6. Vosviewer. VOSviewer - visualizing scientific landscapes. https://www. vosviewer.com/. Accessed January 10, 2020.

7. Wilder-Smith A, Chiew CJ, Lee VJ. Can we contain the COVID-19 outbreak with the same measures as for SARS? Lancet Infect Dis. 2020; 20(5):e102-e107. doi: 10.1016/S1473-3099(20)30129-8

8. Li W, Shi Z, Yu M, et al. Bats are natural reservoirs of SARS-like coronaviruses. Science. 2005;310(5748):676-679. doi: 10.1126/science. 1118391

9. Memish ZA, Perlman S, Van Kerkhove MD, et al. Middle East respiratory syndrome. Lancet (London, England). 2020;395(10229):1063-1077. doi: 10.1016/S0140-6736(19)33221-0

10. Bonilla-Aldana DK, Quintero-Rada K, Montoya-Posada JP, et al. SARS-CoV, MERS-CoV and now the 2019-novel CoV: have we investigated enough about coronaviruses? - a bibliometric analysis. Travel Med Infect Dis. 2020;33:101566. doi: 10.1016/j.tmaid.2020.101566 